STEPHEN SEVERN

A Knot, A Network, A Thing, A World:

Composition as Generative Meaning-Making in Still Life Photography 
STEPHEN SEVERN A Knot, A Network, A Thing, A World: Composition as Generative Meaning-Making in Still Life Photography

\section{A Composition}

It is overcast and the light entering through the window casts soft diffused shadows. The table is positioned to capitalize on the available light; the curtain opens and closes to adjust to the changing light throughout the day. Living high up, the light enters in a different way, it feels more horizontal.

This apartment is a vessel. I'm not sure if it is a ship or a container but its cargo is life, matter, and affect thrown together. Objects are thrown together; the root of the word "object" is a combination of ob "in front of" and jacere "to throw" which applies to both the verb, to oppose, and the noun, a tangible thing perceived by or presented to the senses. Apartments, like objects, are deceptively not static.

This drawer is a vessel: a knot of objects.

This wooden canister is a container and a network of lines.

This incense burner is a thing and a holder of things.

This still life is a composition of rooms in an apartment: a world.

They are emptied of their contents and recomposed, each object repeatedly touched and moved. There is an easy precision to their placement: quickly considered with rote attentiveness to their relation in space and their performance for lens and shutter, window and curtain. 
Elements move towards, cohere, and separate. It is in this ontogenetic and generative coherencethe composition - that meaning is created.

This paper positions still life photography as a non-representational, ontogenetic, and generative coherence of thought, matter, and meaning: what Tim Ingold describes as a knot, ${ }^{1}$ what Donna Haraway describes as a network, ${ }^{2}$ what Martin Heidegger, Bill Brown, and Elizabeth Grosz describe as a thing, ${ }^{3}$ and what Kathleen Stewart describes as a world. ${ }^{4}$

Nigel Thrift, in his book Spatial Formations, locates the construction of meaning in the "manifold of action and interaction." ${ }^{\prime 5}$ He describes locations of action, among which he includes not only human-human or human-environment interactions but also arrangements of objects, as enactments. ${ }^{6}$ This is an important way of discerning non-representational theories as a view of the world comprising an active externalism which creates meaning from thought-in-action rather than an internal view which relies on discourse, ideology, or symbolic representation. ${ }^{7}$ Non-representational theory does not discount meaning but foregrounds its construction in action and relation, similar to Stewart's compositional theory which "tries to register the tactility and significance of the process of coming into form itself."

A non-representational compositional approach to meaning-making in still life photography holds space for a research-creation methodology, one which challenges the separation between thinking and making. ${ }^{9}$ This challenge has also appeared in my research and praxis in explorations of Lambros Malafouris' Material Engagement theory, which he describes as "a radically alternative claim: that human mental life (cognition and affect) is a process genuinely mediated and often constituted by things." ${ }^{10}$ Similarly, Andy Clark and David Chalmers' Extended Mind Theory advocates for an active externalism beyond "the hegemony of skin and skull"11 which drives cognitive processes. ${ }^{12}$ This methodology and theoretical underpinning, like Stewart's compositional theory, locate meaning in process, bred of action and relation.

The photographic images in A Knot, A Network, A Thing, A World present an alternative to photography as representation and/or documentation, instead centring its composition as a moving-towards of human and non-human elements continually coming into being, generating new meanings and compositions.

\section{A Knot}

The drawer opens and the contents shift but remain together. This is not top-drawer stuff, but items relegated to the lower tier of randomness and infrequent use. Expired antacids and bright orange earplugs will be thrown away. The orange plastic case is a provocation of future travel and a reminder of past adventures, unpacked and repacked at each destination. The polaroid now lives in the drawer: an inaccurate representation of the drawer's current contents.

Tim Ingold describes coherence as a knot formed of ontogenetic action:

in a world where things are continually coming into being through processes of growth and movement - that is, in a world of life - knotting is the fundamental principle of coherence. It is the way forms are held together and kept in place within what would otherwise be a formless and inchoate flux. This applies as much to forms of knowledge as to material things, whether made like artefacts or grown like organisms. ${ }^{13}$ 
Ingold's description of coherence as knotting is similar to what Ben Anderson and Paul Harrison call a zone of stabilization, a recursive patterning: both descriptions accounting for ontogenetic action and relation. This holding-together is a reciprocity, not subject authoring object or mind effecting matter, but a feedback of constant relation involving all elements, practices, participations, and affordances. ${ }^{14}$ Knots are perpetually being untangled and reknotted.

Still life photography is knowledge-making born of matter and action.

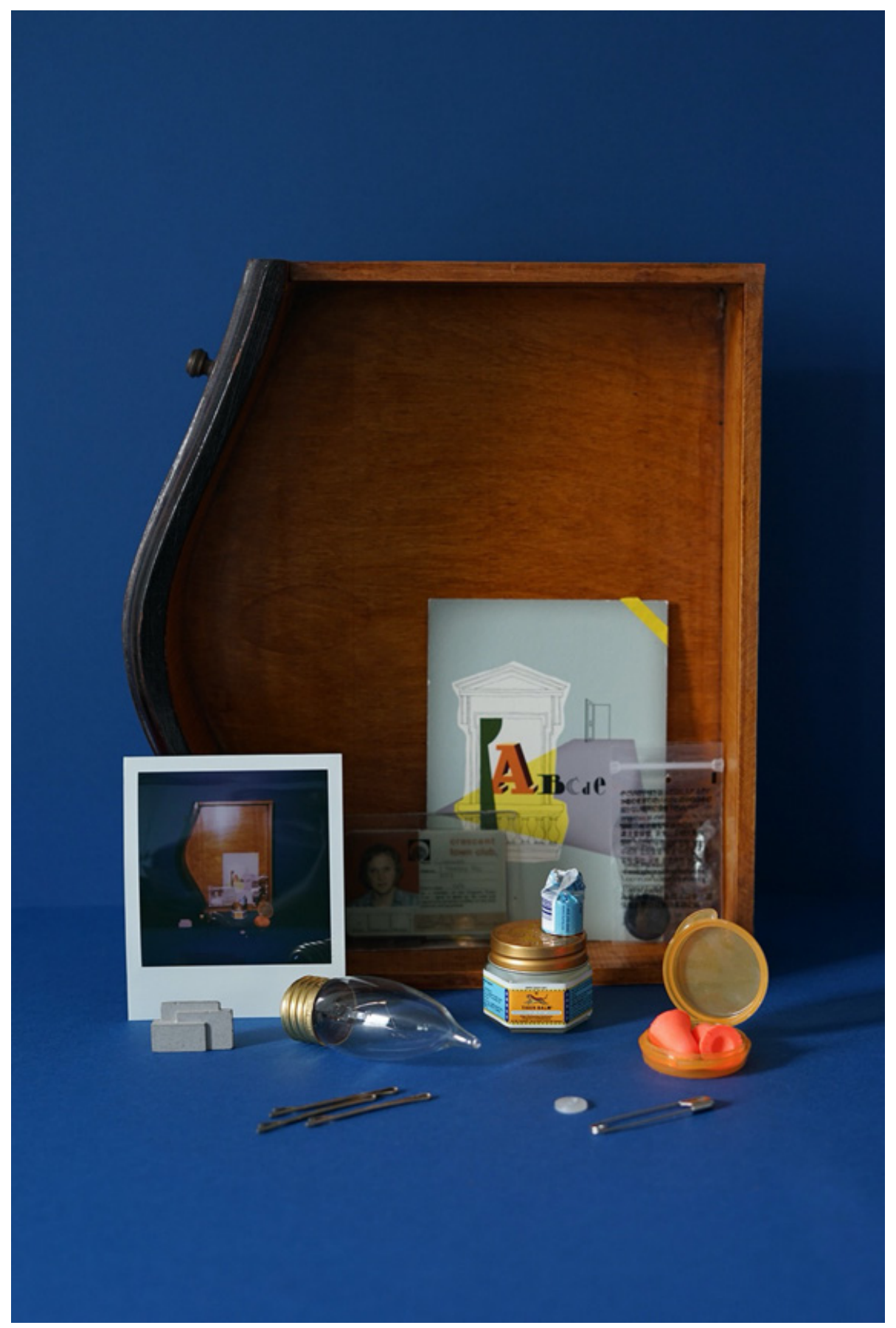

A Knot, 2021, digital photograph. 


\section{A Network}

Pebbles tumbled into smoother and rounder shapes wash up on the shore with shells formed from the mantle of mollusks. Some find their way into a hand-carved spalted wood vessel discovered in an antique store a stone's throw from their Fife Coastal home: a border between land and sea.

Spalted wood is also known as web wood because of the zone lines it contains. The dark lines are a result of a mycelial defence: a zone of interaction where the fungus protects its territory from its fungal neighbours. It is rare for this to occur in living wood. There are a specific set of conditions that enable fungal colonization and a short window of usability during the growth of the zone lines before the wood decays.

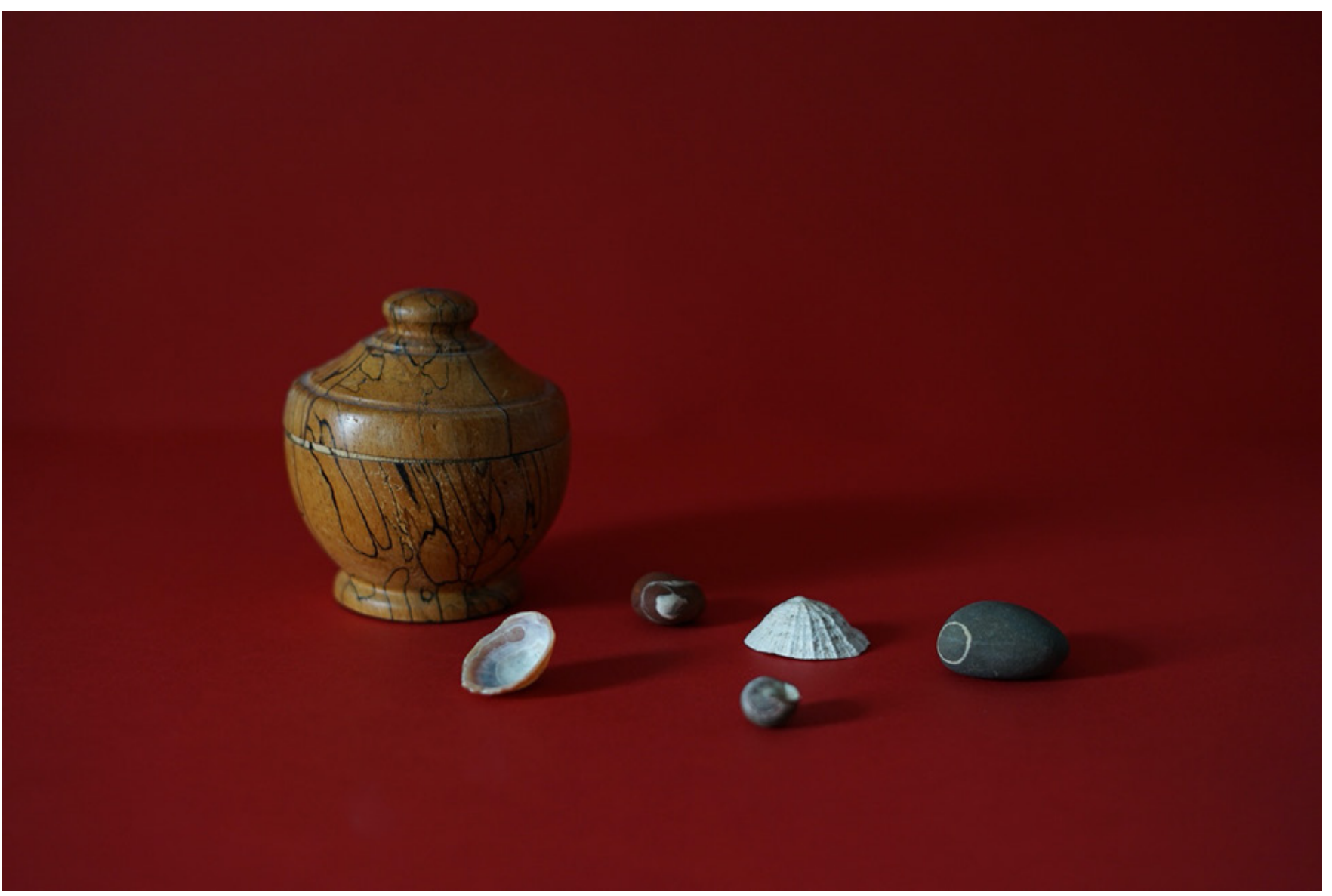

A Network, 2021, digital photograph. 
A network, like a knot, is an arrangement of intersecting lines: lines of movement, lines of force. The arrangement is an act of coherence of heterogeneous elements, not an assemblage; arrangements favour multiplicity, unlike assemblages, which favour unity. ${ }^{15}$

In her book Staying with the Trouble: Making Kin in the Chthulucene, Donna Haraway describes a transdisciplinary collaboration of string figures that connect human and nonhuman ecologies, affects, technologies, and performances: a tentacular network, a "sympoiesis" of "making-with." 16 Making-with is not autopoietic, is not self-generative. Making-with is a composition that accounts for action, multiplicity, and a becoming-with. Becoming-with accommodates movement, lines of force, unpredictability, transformation, and regeneration.

Still life photography is sympoietic.

\section{A Thing}

The thing stands in goat-legged contrapposto: a slight leaning towards, owing to a missing bolt. A shiny modern replacement bolt wasn't helping, so it was removed but still lives within the vessel. Why does it have those holes in the lid?: an unspecific specificity. On one of the boy's visits, he lifts the lid expecting to find the scarab beetle encased in resin that he knows is always there, but a different object is revealed: a surprise. He is older now and no longer interested in its contents, so it is used to house a lighter and matches - a fitting function since its identification as an incense burner.

Is the thing a catchall? Not in the sense of it being a receptacle for odds and ends, but in its definition as something that covers a wide variety of items, situations, or possibilities?

Things occur in the world as verbs, unlike objects which simply exist as nouns. ${ }^{17}$ Bill Brown describes a similar shift: a shift from object to subject when the thing's common function as an object ceases and it become physically or metaphysically irreducible to an object: "The story of objects asserting themselves as things, then, is the story of a changed relation to the human subject and thus the story of how the thing really names less an object than a particular subject-object relation."18 The thing is in excess of the object and can take the form of "a still life, or a scene of some potential." 19 The potential, asserts Elizabeth Grosz, is the thing's incitement to action. ${ }^{20}$

Still life photography is in excess of the object. 


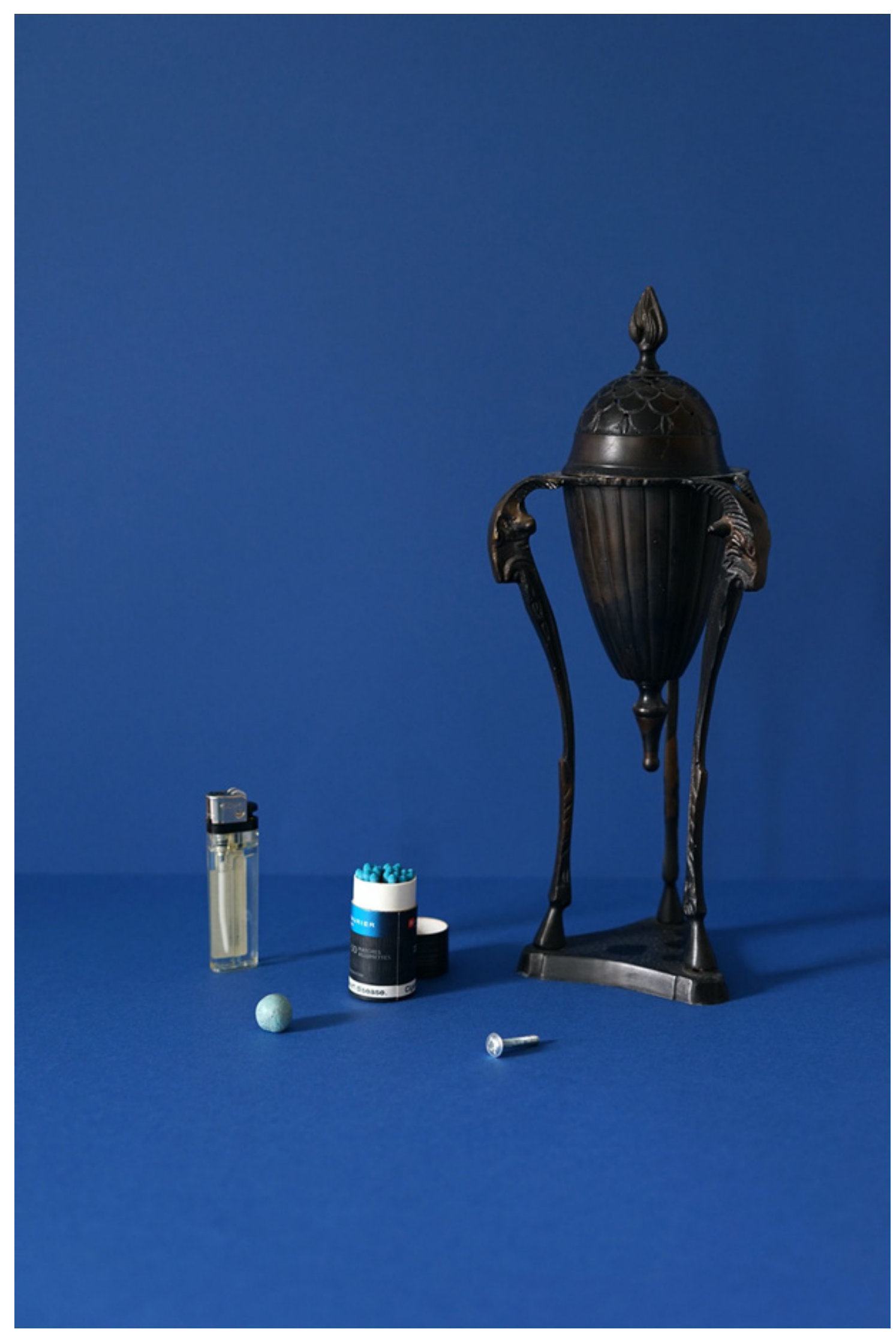

A Thing, 2021, digital photograph. 


\section{A World}

A photo, a spoon, some pills, an awl, a clip, a rock, a cube, a vase, dead leaves, a camera, the paper, the window, the curtains, the light, a table, a wall, a pandemic, an apartment, a human, a composition: "Disparate and incommensurate elements (human and non-human, given and composed) cohere and take on force as some kind of real, a world. ${ }^{921}$

Anderson and Harrison describe the incitement to action-the generative force of non-representation-as being "marked by an attention to events and the new potentialities for being, doing, and thinking that events may bring forth" and oriented to an open-ended future. ${ }^{22}$ This constant regeneration of an undefined futurity opens us up to the creation of future worlds and possibilities free from the encumbrance of preconceived representation. We do not know a world until we inhabit it, and meaning is enacted and reenacted through movement; it is constructivist, made-up, and always real. ${ }^{23}$

Still life photography is a generative force. 


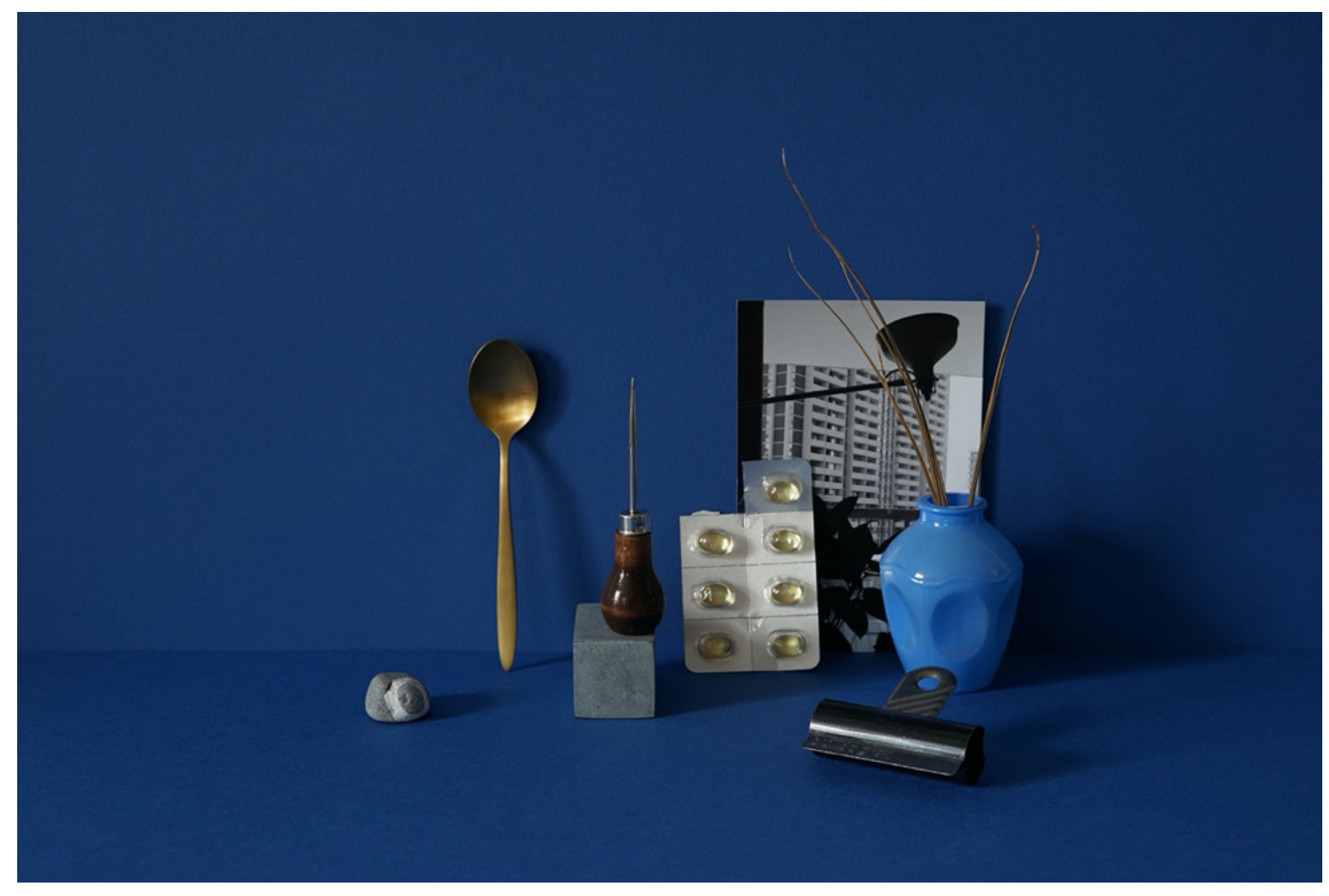

A World, 2021, digital photograph. 


\section{A Composition (a conclusion)}

It is overcast and the light entering through the window casts soft diffused shadows. The table is still positioned to capitalise on the available light: the curtains drawn wide to let in as much of the day as possible. This laptop sits in a red and blue paper scene amongst the detritus of compositions un-knotted, re-networked, and re-worlded. I have been sitting inside this still life world for a month now. The paper is frayed and creased, not in the pathetic fallacy of a decaying photography set, but simply in its service as a desk. The paper is covered in a pink dust that has eroded off of a geode. Why have I not put these things away? Did I need more time with these things?

My interest in human-object relations and still life photography brought me to Erin Manning's ideas of a research-creation methodology challenging the separation between thinking and making, ${ }^{24}$ and Lambos Malafouris' Material Engagement theory which challenges the separation between mind and matter. ${ }^{25}$ Stewart's compositional theory, which "pull[s] matter and mind into a making: a worlding,"26 offers a non-representational model for a still life photography practice and for the formation of meaning in "thought-as-action." 27

Inspired by Manning's assertion that we are in a constant process of individuation that never arrives at a finalized state of identity, ${ }^{28}$ my research and practice objectives have been to observe objects in this same light: not as representations of our identity, but in a process of becoming alongside humans, whose relations intertwine and transform through time, space, and movement. A non-representational approach aligns well with these objectives. My research has previously centred on the question of how human and object ontogenies intertwine in matrices of transformation? but is now moving towards observing meaningmaking in the ontogenetic and generative coherence of composition. The shift is from a view of matter as internalized bounded-subjects towards an active and ever-evolving externalism. ${ }^{29}$ This ever-evolving externalism is an invitation to all matter, meanings, minds, affects, ecologies, and movements.

Viewed through a non-representational lens, photography does not stop the world in thought. A still life photograph is a composition - an event - which lives on in a generative ontogenetic state of forming and reforming, composing and recomposing new knots, networks, things, and worlds. 


\section{Endnotes}

1 Tim Ingold, The Life of Lines (New York: Routledge, 2015), 14.

2 Donna J. Haraway, Staying with the Trouble: Making Kin in the Chthulucene (London: Duke University Press, 2016), 63.

3 Martin Heidegger, "The Thing," in Poetry, Language, Thought, trans. Albert Hofstadter, (New York: Harper Perennial Modern Thought, 2013), 179-180; Bill Brown, “Thing Theory," Critical Inquiry 28, no. 1, (Autumn 2001): 3-5; Elizabeth Grosz, "The Thing," in The Object Reader, ed. Fiona Candlin and Raiford Guins (New York: Routledge, 2009), 125.

4 Kathleen Stewart, "Tactile Compositions," in Objects and Materials, ed. Penny Harvey et al. (New York: Routledge, 2015), 119.

$5 \quad$ Nigel J. Thrift, Spatial Formations (London: Sage, 1996), 6.

6 Thrift, 9.

7 Ben Anderson and Paul Harrison, "The Promise of Non-Representational Theories," in Taking-Place: Non-Representational Theories and Geography (Farnham: Ashgate, 2010): 2; Thrift, 6.

8 Stewart, "Tactile Compositions," 119.

9 Sarah E. Truman, et al., "The Intimacies of Doing Research-Creation," in Knowings and Knots: Methodologies and Ecologies in Research-Creation, ed. Natalie Loveless (Edmonton: University of Alberta Press, 2019) 228.

10 Lambros Malafouris, "Thinking as 'Thinging': Psychology with Things," Current Directions in Psychological Science 29, no. 1, (February 2020): 4.

11 Andy Clark and David Chalmers, "The Extended Mind" Analysis 58, no. 1, (1998): 18.

12 Clark, 7.

13 Ingold, The Life of Lines, 14.

14 Anderson, "The Promise of Non-Representational Theories," 7-8.

15 Thomas Nail, "What is an Assemblage?" SubStance 46, no. 1, (2017): 22.

16 Haraway, Staying with the Trouble.

17 Ingold, The Life of Lines, 16.

18 Brown, "Thing Theory," 4.

19 Stewart, "Tactile Compositions," 119.

20 Grosz, "The Thing," 125.

21 Stewart, "Tactile Compositions," 119.

22 Anderson, "The Promise of Non-Representational Theories," 19, 3.

23 Anderson, 9.

24 Sarah E. Truman, et al., "The Intimacies of Doing Research-Creation,” 228.

25 Lambros Malafouris, "Thinking as "Thinging": 4.

26 Stewart, "Tactile Compositions," 119.

27 Thrift, Spatial Formations, 6.

28 Erin Manning, Politics of Touch Sense, Movement, Sovereignty (Minneapolis: University of Minnesota Press, 2007), 90.

29 Tim Ingold, "Rethinking the Animate, Re-animating Thought," Ethnos 71, no. 1, (2011): 12-14. 


\section{Bibliography}

Anderson, Ben and Paul Harrison. "The Promise of NonRepresentational Theories." In Taking-Place: NonRepresentational Theories and Geography, 1-36. Farnham: Ashgate, 2010. https://www.ashgate.com/ isbn/9780754672791

Brown, Bill. "Thing Theory." Critical Inquiry, 28, no. 1, (Autumn 2001): 1-22. https://www.jstor.org/ stable/1344258.

Chalmers, David and Andy Clark. "The Extended Mind." Analysis, 58, no. 1, (1998): 7-19. https://www. jstor.org/stable/3328150.

Grosz, Elizabeth. "The Thing." In The Object Reader, 124138. Edited by Fiona Candlin and Raiford Guins. New York: Routledge, 2009.

Haraway, Donna J. Staying with the Trouble: Making Kin in the Chthulucene. London: Duke University Press, 2016.

Heidegger, Martin. "The Thing." In Poetry, Language, Thought, 160-184. Translated by Albert Hofstadter. New York: Harper Perennial Modern Thought, 2013.

Ingold, Tim. "Rethinking the Animate, Re-animating Thought." Ethnos, 71, no. 1, (2011): 9-20. https://doi.org/10.1080/00141840600603111

The Life of Lines. New York: Routledge, 2015.
Malafouris, Lambros. "Thinking as 'Thinging': Psychology with Things." Current Directions in Psychological Science, 29, no. 1, (February 2020): 3-8. https:// doi.org/10.1177/0963721419873349

Manning, Erin. Politics of Touch Sense, Movement, Sovereignty. Minneapolis: University of Minnesota Press, 2007.

Nail, Thomas. "What is an Assemblage?" SubStance, 46, no. 1, (2017): 21-37. muse.jhu.edu/article/650026.

Stewart, Kathleen. “Tactile Compositions." In Objects and Materials, 119-127. Edited by Penny Harvey, Eleanor Conlin Casella, Gillian Evans, Hannah Knox, Christine McLean, Elizabeth B. Silva, Nicholas Thoburn, and Kath Woodward. New York: Routledge, 2015.

Thrift, Nigel J. Spatial Formations. London: Sage, 1996.

Truman, Sarah E. Interview with Natalie Loveless, Erin Manning, Natasha Myers, and Stephanie Springgay. "The Intimacies of Doing Research-Creation." In Knowings and Knots: Methodologies and Ecologies in Research-Creation, 221-249. Edited by Natalie Loveless. Edmonton: University of Alberta Press, 2019. 